\title{
Analysis on insulator-metal transition in yttrium doped LSMO from electron density distribution
}

\author{
S ISRAEL* ${ }^{*}$ S SARAVANA KUMAR, R RENURETSON, R A J R SHEEBA ${ }^{\dagger}$ and R SARAVANAN ${ }^{\dagger}$ \\ Department of Physics, The American College, Madurai 625 002, India \\ $\dagger^{\dagger}$ Department of Physics, The Madura College, Madurai 625 011, India
}

MS received 21 August 2010; revised 12 July 2011

\begin{abstract}
Yttrium doped LSMO ( $\left(\mathrm{La}_{1-x} \mathrm{Sr}_{x} \mathrm{MnO}_{3}\right)$ was prepared using sol-gel technique and analysed for the insulator-metal transition from charge density variation in the unit cell with respect to different stoichiometric inclusion of yttrium. X-ray powder diffraction profiles of the samples were obtained and the well known Rietveld method and a versatile tool called maximum entropy method (MEM) were used for structural and profile refinement. The charge density in the unit cell was constructed using refined structure factors and was analysed. The charge ordering taking place in the insulator-metal transition was investigated and quantified. The insulator-metal transition was found to occur when $20 \%$ of $\mathrm{La} / \mathrm{Sr}$ atoms were replaced by yttrium. The changes in the charge environment have also been analysed.
\end{abstract}

Keywords. LSMO; X-ray diffraction; MEM; charge density; insulator - metal transition.

\section{Introduction}

Rare-earth manganites doped with alkaline-earth metals are important materials of fundamental and technological interests (Yakel 1955; Saitoh et al 1995; Urushibara et al 1995; Lyu et al 1998; Alexandrov and Bratkovsky 1999; Tokura and Tomioka 1999). These materials exhibit colossal magnetoresistance (CMR), which has a great potential in magnetic devices. The colossal magnetoresistive manganites are among the most studied materials in condensed matter physics (Tokura 2000). Most of the extensive research work carried out on the manganites having the general formula, $R_{1-x} A_{x} \mathrm{MnO}_{3}(\mathrm{R}$, rare earth trivalent cation, $A$, divalent cation), exhibits dual novel properties such as negative colossal magneto resistance and the metal-insulator (M-I) transition in the vicinity of magnetic transition. These have been explained in terms of correlation between spin, charge and orbital degrees of freedom (Vachhani et al 2007).

The anti ferromagnetic $\mathrm{LaMnO}_{3}$ is known as an insulator at low temperature. Alkali earth metals like $\mathrm{Sr}$ or $\mathrm{Ca}$ doped $\mathrm{LaMnO}_{3}$ i.e. $\mathrm{La}_{1-x} \mathrm{Sr}_{x} \mathrm{MnO}_{3}$ and $\mathrm{La}_{1-x} \mathrm{Ca}_{x} \mathrm{MnO}_{3}$ with a large $x$, are anti-ferromagnetic. They have a decreasing resistivity $\rho$ with $T$. So it is also described as an insulator despite the fact that the decrease of $\rho$ is not exponential and $\rho$ has an order of only $10^{2} \Omega$-cm when $T \rightarrow 0$ (Tsai et al Private Communication; Arima et al 1993; Krishnan and Ju 1999; Xiong et al 1999). With $x$ less than about 0.50 it exhibits ferromagnetic properties at low temperature and has an

\footnotetext{
*Author for correspondence (israel.samuel@gmail.com)
}

increasing resistivity $\rho$ with $T$, so that these manganites are described as ferromagnetic metals, though the $\rho$ of these manganites has an order between 1 and $10^{-3} \Omega$-cm. This is much larger than the typical $\rho$ of metals of an order of $10^{-6} \Omega$-cm at room temperature. This kind of half metallic electric behaviour makes the manganites more interesting and motivates one to study its behaviour in terms of correlations between charge and spin.

The half metallic properties of $\mathrm{La}_{1-x} \mathrm{Sr}_{x} \mathrm{MnO}_{3}$ (LSMO) are of great importance in application in spintronics. The electronic properties of LSMO, as described by the band theory are nearly half-metallic (Picket and Singh 1997; Livesay et al 1999) reflecting the so-called transport half-metallic behaviour (Nadgorny et al 2001). However, the fascinating electronic and magnetic properties of LSMO, including colossal magneto resistance, indicate that the electronic structure is more complex than the standard band theory picture (Tokura and Tamioka 1999). Banach et al discussed on the self-interaction corrected local spin density approximation calculation leading to the presence of half metallic state in LSMO.

Gaur and Varma (2006) worked on nano phasic LSMO prepared using sol-gel method and sintered at different temperatures ranging from 600 to $1000^{\circ} \mathrm{C}$. It was shown that the transport and magneto resistive properties of LSMO samples strongly depend on the sintering temperature. A substantial decrease in the insulator-metal transition temperature $\left(T_{\mathrm{IM}}\right)$ and an enhancement in resistivity are found on lowering the sintering temperature. Furthermore, a reduction in magnetization and a slight decrease in paramagneticferromagnetic $(\mathrm{PM}-\mathrm{FM})$ transition temperature $\left(T_{\mathrm{c}}\right)$ has been observed as the sintering temperature decreases. The 
magneto resistance (MR) at $T<T_{\mathrm{c}}$ increases on decreasing the sintering temperature and increasing the applied magnetic field. The enhancement in MR on decreasing the sintering temperature is explained by enhanced spin-polarized tunneling by assuming an increase of the grain boundary contribution.

The $\mathrm{La}_{1-x} \mathrm{Sr}_{x} \mathrm{MnO}_{3}$ (LSMO) compound with $x=0 \cdot 2-$ 0.4 are interesting materials that exhibit consecutive phase transition from paramagnetic (PM) state to ferromagnetic (FM) state and then to charge-ordered (CO) state accompanied by a sharp drop in resistivity (Janker and van Santen 1950; van Santen and Janker 1950). Thus, LSMO is a good material that can be used in the investigation of the lattice strain effect in the PM, FM and CO states, respectively (Zheng et al 2007). The inclusion of transition metal element like yttrium(Y) at the La/Sr site of LSMO induces insulatormetal transition and this behaviour depends on the stoichiometric composition of $\mathrm{Y}$ in LSMO. This behaviour was studied on $\mathrm{Y}_{x} \mathrm{La}_{1-x-y} \mathrm{Sr}_{y} \mathrm{MnO}_{3}$ with $y=0.3$ by Renuretson (2007) and they have investigated also on its electrical and magnetic transport characteristics and their dependence on the stoichiometric inclusion of yttrium. They have found that zero field resistivity in the material increases as the doping concentration of $\mathrm{Y}$ increases. Also, it was found that the insulator-metal transition temperature decreases from 185 to $170 \mathrm{~K}$ when the concentration of $\mathrm{Y}$ increases from $x=0$ to 0.2 and then the same increases to $175 \mathrm{~K}$ when $x$ increases to $0 \cdot 3$. At the same time the magneto resistance measured at room temperature shows the trend of weakening of the ferromagnetic order and increasing of magnetic disorder as the doping concentration increases. These behaviours depend very much on the ordering of charges in the lattice and are also influenced by the inclusion of $\mathrm{Y}$ at the lattice site of $\mathrm{La} / \mathrm{Sr}$. A chemically driven insulator-metal transition in nonstoichiometric and amorphous gallium oxide was reported by Nagarajan (2008). They have demonstrated through experimental studies and density-functional theory calculations that the conductivity jump takes place at a critical gallium concentration and it is induced by crystallization of stoichiometric $\mathrm{Ga}_{2} \mathrm{O}_{3}$ within the metastable oxide matrix in chemical terms by a disproportionation.

So far, none of these works have yielded any information on the arrangement of charges that reveals reported magnetic or electric behaviour of the materials. And hence, it was proposed that the charge density analysis in the unit cell of title material $\mathrm{Y}_{x} \mathrm{La}_{1-x-y} \mathrm{Sr}_{y} \mathrm{MnO}_{3}$ may give intricate details on how the charge is distributed and on changes due to the variation in concentration of dopant material $\mathrm{Y}$ that would have implication on the observed electric and magnetic ordering/disordering. This has motivated us to estimate the charge and to map it along the lattice in order to see how the charge actually behaves and distributes itself in contributing to ferromagnetic ordering and insulator-metal transition. Thus this work concentrates on charge density in the unit cell of the chosen material, and for that purpose, the X-ray diffraction pattern was utilized, refined and analysed using Rietveld refinement and MEM analysis.

\section{Sample preparation}

Samples of $\mathrm{Y}_{x} \mathrm{La}_{1-x-y} \mathrm{Sr}_{y} \mathrm{MnO}_{3}(y=0.3$ and $x=0,0 \cdot 1$, $0 \cdot 2,0 \cdot 3)$ were synthesized via sol-gel method. The required amounts of high purity nitrates of $\mathrm{La}, \mathrm{Sr}$ and $\mathrm{Mn}$ were dissolved in double distilled water to form an aqueous solution. An equal amount of ethylene glycol was added to this solution with continuous stirring. This solution was then heated on a hot plate at a temperature of $40-80^{\circ} \mathrm{C}$ until a dry quick brown sol was formed. This was further decomposed in an oven at $200^{\circ} \mathrm{C}$ to obtain a dry fluffy material. The polymeric precursor thus obtained was calcined at $600^{\circ} \mathrm{C}$ for $12 \mathrm{~h}$. The resulting powder was ground well and pressed into pellets and sintered at $700^{\circ} \mathrm{C}$ for $15 \mathrm{~h}$ for each composition. The samples (for $x=0,0 \cdot 1,0 \cdot 2,0 \cdot 3$ ) are hereafter referred to as $\mathrm{S} 1, \mathrm{~S} 2, \mathrm{~S} 3$ and $\mathrm{S} 4$, respectively.

The prepared samples were analysed for the content of individual constituent in the material from EDAX analysis that shows the atomic weight percentage of the constituents in the sample. The resultant composition presented in table 1 confirms inclusion of yttrium in the stoichiometrically prepared samples, thus obeying the desired molecular formula. SEM micrographs of the prepared samples are presented in figure 1. These figures show grain structure of the prepared samples and the analysis of the grain size of the particles shows that for $\mathrm{S} 1-\mathrm{S} 4$, the size ranges from 7.8 to $10.2 \mathrm{~nm}$.

\section{XRD analysis}

The powder X-ray data were collected for all the samples using X-PERT PRO (Philips, The Netherlands) X-ray diffractometer with a monochromatic incident beam, which offers pure $\mathrm{CuK}_{\alpha 1}$ radiation. The $2 \theta$ range of $\mathrm{X}$-ray intensity data is from $5^{\circ}$ to $75^{\circ}$. The raw profile of the powder diffraction pattern for yttrium doped LSMO is presented in figure 2. The X-ray diffraction data of the samples were refined for their structural and stoichiometric parameters using the well known Rietveld technique.

The Rietveld (1969) method was used for refining structural parameters (fractional coordinates, atomic displacement parameters, occupation factors and lattice parameters) using the software Jana2006 (Petricek et al 2000) directly from whole powder diffraction patterns. In this method, the observed profiles were matched with the profiles constructed similarly by using pseudo-voigt (Wertheim et al 1974) profile shape function of Thompson et al (1987). It was modified, to some extent, to accommodate various Gaussian FWHM

Table 1. EDAX analysis of the prepared samples.

\begin{tabular}{lcrrccc}
\hline Sample & $x$ & La & Sr & Y & Mn & O \\
\hline$S 1$ & 0.0 & 11.96 & 6.93 & 3.56 & 18.72 & 45.28 \\
$S 2$ & 0.1 & 10.84 & 7.03 & 3.72 & 19.97 & 43.31 \\
$S 3$ & 0.2 & 8.99 & 9.02 & 4.64 & 19.45 & 38.10 \\
$S 4$ & 0.3 & 8.46 & 11.04 & 4.84 & 22.70 & 42.66 \\
\hline
\end{tabular}



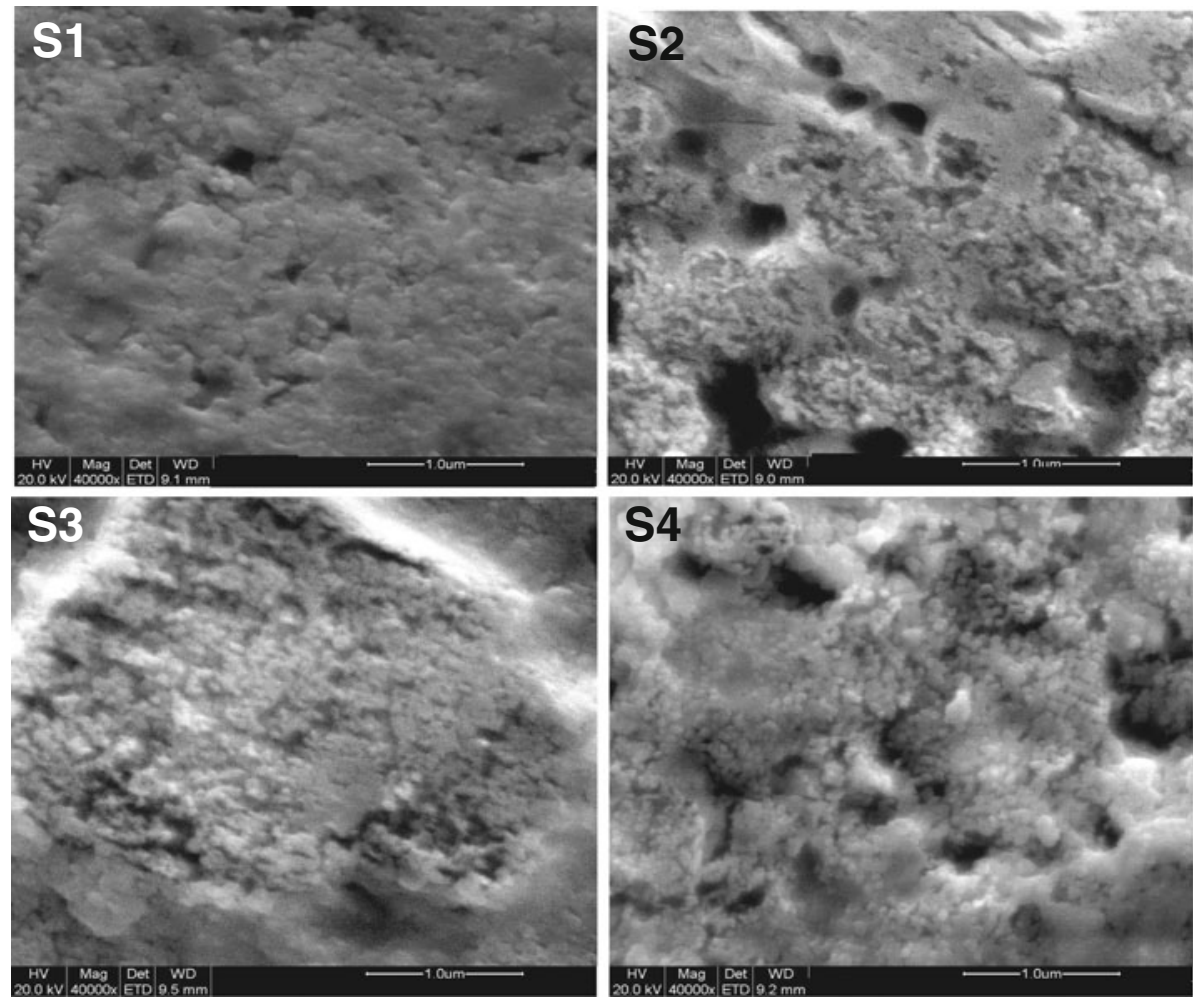

Figure 1. SEM micrographs of grown sample.
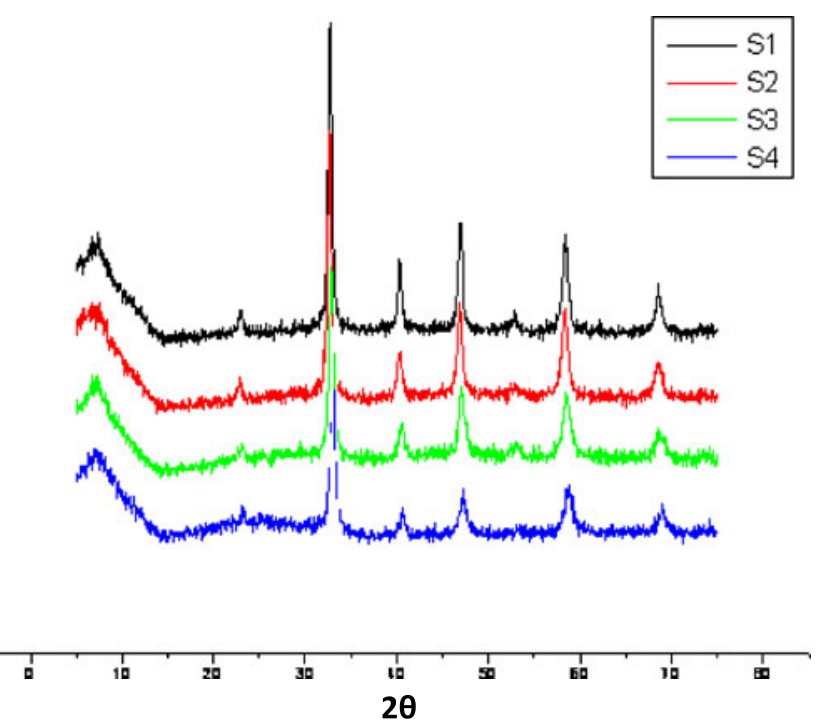

Figure 2. Raw powder profile for yttrium doped LSMO.

parameters and Scherrer coefficient, P, for Gaussian broadening. The profile asymmetry was also introduced by employing multi-term Simpson rule integration devised by Howard (1982). It incorporates symmetric profile shape function with different coefficients for weights and peak shift. Jana2006 also employs the correction for the preferred orientation which is independent of diffraction geometry according to the March-Dollase function (Israel et al 2003, 2004). The
Table 2. Refined structural parameters.

\begin{tabular}{lcccccccc}
\hline Sample & $x$ & $a(\AA)$ & $b(\AA)$ & $c(\AA)$ & $\alpha$ & $\beta$ & $\gamma$ & $V\left(\AA^{3}\right)$ \\
\hline$S 1$ & $0 \cdot 0$ & $5 \cdot 4913$ & $5 \cdot 4913$ & $13 \cdot 1373$ & 90 & 90 & 120 & $343 \cdot 0778$ \\
$S 2$ & $0 \cdot 1$ & $5 \cdot 5021$ & $5 \cdot 5021$ & $13 \cdot 0958$ & 90 & 90 & 120 & $343 \cdot 3463$ \\
$S 3$ & $0 \cdot 2$ & $5 \cdot 5029$ & $5 \cdot 5029$ & $13 \cdot 3420$ & 90 & 90 & 120 & $349 \cdot 9036$ \\
$S 4$ & $0 \cdot 3$ & $5 \cdot 3639$ & $5 \cdot 3639$ & $12 \cdot 1617$ & 90 & 90 & 120 & $303 \cdot 0365$ \\
\hline
\end{tabular}

calculated profiles thus evolved were compared with the observed ones. During the refinement, the trial cell parameters were introduced as $a=b=5.503 \AA$ and $c=13.342 \AA$ for all the samples. The position of the atoms for $\mathrm{La}, \mathrm{Sr}$ and $\mathrm{Y}$ was taken as $(0,0,0 \cdot 25)$ with relevant stoichiometric compositions and for oxygen $(0.4592,0,0.25)$ whereas Mn atoms were placed at the origin. The symmetric group of $R-3 c$ was used for positioning the atoms in the unit cell. The raw intensities thus refined have yielded structural parameters, structure factors and the reliability indices that are presented in tables 2, 3 and 4, respectively. The refined cell parameters show inconsistent and slight variation in the size of unit cell in all three dimensions and they are found to decrease in $\vec{a}$ and $\vec{b}$ directions as the concentration $(x)$ of yttrium increases from 0 to $0 \cdot 2$ and then decreases to $0 \cdot 3$. In $\vec{c}$ direction the cell length decreases for $\mathrm{S} 1$ and $\mathrm{S} 2$ and increases for $\mathrm{S} 2$ and again decreases from thereon. The list of refined structure factors (table 3 ) is considered to be very accurate as evidenced from the $R$-factors presented in table 4 . Successful refinement has 
Table 3. Comparison of observed and calculated structure factors.

\begin{tabular}{|c|c|c|c|c|c|c|c|c|c|c|}
\hline \multirow[b]{2}{*}{$h$} & \multirow[b]{2}{*}{$k$} & \multirow[b]{2}{*}{$l$} & \multicolumn{2}{|c|}{$S 1$} & \multicolumn{2}{|c|}{$S 2$} & \multicolumn{2}{|c|}{$S 3$} & \multicolumn{2}{|c|}{$S 4$} \\
\hline & & & $F_{\mathrm{o}}$ & $F_{\mathrm{c}}$ & $F_{\mathrm{o}}$ & $F_{\mathrm{c}}$ & $F_{\mathrm{o}}$ & $F_{\mathrm{c}}$ & $F_{\mathrm{O}}$ & $F_{\mathrm{c}}$ \\
\hline 1 & -1 & 2 & 95.5572 & $96 \cdot 3961$ & $86 \cdot 6512$ & $87 \cdot 0058$ & $77 \cdot 8699$ & $77 \cdot 9434$ & $68 \cdot 3951$ & $68 \cdot 3738$ \\
\hline 2 & -1 & 0 & $295 \cdot 328$ & 295.013 & $285 \cdot 560$ & $286 \cdot 677$ & 278.737 & 278.649 & 267.482 & $267 \cdot 502$ \\
\hline 1 & 0 & 4 & 297.418 & $296 \cdot 976$ & $287 \cdot 144$ & $288 \cdot 249$ & 282.005 & $281 \cdot 905$ & $264 \cdot 702$ & $264 \cdot 680$ \\
\hline 2 & -1 & 3 & $28 \cdot 2633$ & $28 \cdot 2628$ & $28 \cdot 1630$ & $28 \cdot 2642$ & 28.4125 & 28.4047 & $27 \cdot 2161$ & $27 \cdot 2016$ \\
\hline 2 & 0 & 2 & $182 \cdot 862$ & $182 \cdot 130$ & $174 \cdot 415$ & 175.053 & $168 \cdot 447$ & $168 \cdot 330$ & $157 \cdot 268$ & $157 \cdot 274$ \\
\hline 0 & 0 & 6 & $185 \cdot 414$ & $186 \cdot 134$ & $177 \cdot 916$ & $178 \cdot 543$ & $174 \cdot 290$ & $174 \cdot 141$ & $154 \cdot 874$ & $155 \cdot 013$ \\
\hline 2 & -2 & 4 & $326 \cdot 526$ & $325 \cdot 907$ & $317 \cdot 875$ & 319.008 & $314 \cdot 345$ & 314.412 & $293 \cdot 373$ & $294 \cdot 191$ \\
\hline 3 & -1 & 1 & 19.5249 & 19.4502 & $19 \cdot 4206$ & 19.4898 & $19 \cdot 5152$ & $19 \cdot 5027$ & $18 \cdot 7830$ & 18.7856 \\
\hline 3 & -2 & 2 & $75 \cdot 5782$ & $75 \cdot 3550$ & 68.8895 & $69 \cdot 1350$ & $63 \cdot 1662$ & $63 \cdot 1185$ & $56 \cdot 0730$ & 56.0786 \\
\hline 2 & -1 & 6 & $70 \cdot 1936$ & 69.9832 & 63.4575 & 63.6837 & $58 \cdot 0163$ & 58.0251 & $50 \cdot 0972$ & $50 \cdot 1397$ \\
\hline 3 & 0 & 0 & $211 \cdot 748$ & $211 \cdot 670$ & $205 \cdot 364$ & $206 \cdot 096$ & $200 \cdot 578$ & $200 \cdot 575$ & $189 \cdot 542$ & $189 \cdot 665$ \\
\hline 3 & -1 & 4 & $204 \cdot 156$ & $204 \cdot 031$ & $197 \cdot 504$ & $198 \cdot 208$ & $193 \cdot 604$ & $193 \cdot 571$ & $179 \cdot 850$ & 179.707 \\
\hline 1 & -1 & 8 & $198 \cdot 941$ & $198 \cdot 648$ & $191 \cdot 517$ & $192 \cdot 200$ & $190 \cdot 201$ & $190 \cdot 126$ & $167 \cdot 482$ & $167 \cdot 515$ \\
\hline 3 & -2 & 5 & 14.6794 & $14 \cdot 6628$ & 14.6096 & $14 \cdot 661$ & $14 \cdot 8003$ & $14 \cdot 8137$ & $13 \cdot 6154$ & $13 \cdot 6231$ \\
\hline 4 & -2 & 0 & $214 \cdot 601$ & $214 \cdot 723$ & 209.407 & $210 \cdot 154$ & $204 \cdot 792$ & 205.476 & 193.485 & 193.438 \\
\hline 2 & 0 & 8 & $216 \cdot 475$ & $216 \cdot 201$ & $209 \cdot 925$ & $210 \cdot 673$ & $209 \cdot 351$ & $209 \cdot 910$ & $184 \cdot 017$ & 183.973 \\
\hline 4 & -3 & 1 & 22.5998 & $22 \cdot 6081$ & 22.5967 & $22 \cdot 6772$ & $22 \cdot 7204$ & 22.6919 & 21.5309 & $21 \cdot 5292$ \\
\hline 4 & -2 & 3 & 1.5746 & $1 \cdot 5752$ & $1 \cdot 5732$ & 1.5788 & $1 \cdot 5863$ & $1 \cdot 5843$ & 1.4870 & 1.4863 \\
\hline 3 & -1 & 7 & 11.4185 & 11.4350 & $11 \cdot 3746$ & 11.4152 & 1.6280 & 11.6205 & $10 \cdot 2974$ & $10 \cdot 3141$ \\
\hline 4 & -1 & 2 & $54 \cdot 8408$ & 54.9391 & $50 \cdot 1553$ & $50 \cdot 3341$ & $45 \cdot 8521$ & $45 \cdot 8632$ & $40 \cdot 3267$ & $40 \cdot 3690$ \\
\hline 2 & -1 & 9 & $12 \cdot 0419$ & $12 \cdot 0602$ & 11.9590 & $12 \cdot 0017$ & $12 \cdot 3588$ & $12 \cdot 3563$ & $10 \cdot 5008$ & $10 \cdot 5058$ \\
\hline 3 & 0 & 6 & 62.9367 & $63 \cdot 0213$ & $58 \cdot 2374$ & $58 \cdot 4450$ & $54 \cdot 3628$ & 54.4375 & $47 \cdot 2866$ & $47 \cdot 3613$ \\
\hline 3 & -3 & 6 & 62.9367 & 63.0213 & $58 \cdot 2374$ & $58 \cdot 4450$ & $54 \cdot 3628$ & 54.4375 & $47 \cdot 2866$ & $47 \cdot 3613$ \\
\hline 1 & 0 & 10 & $56 \cdot 2390$ & $56 \cdot 4029$ & 51.5207 & $51 \cdot 7044$ & $48 \cdot 1100$ & $48 \cdot 2084$ & $39 \cdot 8383$ & 39.9141 \\
\hline 4 & -3 & 4 & $144 \cdot 025$ & 143.709 & $138 \cdot 947$ & 139.442 & $135 \cdot 594$ & 135.839 & $124 \cdot 442$ & $124 \cdot 563$ \\
\hline 3 & -2 & 8 & $145 \cdot 425$ & $145 \cdot 272$ & $140 \cdot 118$ & $140 \cdot 617$ & $138 \cdot 280$ & 138.726 & $121 \cdot 325$ & $121 \cdot 441$ \\
\hline 4 & -1 & 5 & $18 \cdot 0292$ & 18.0646 & $18 \cdot 0224$ & 18.0867 & $18 \cdot 2807$ & $18 \cdot 2399$ & $16 \cdot 6113$ & $16 \cdot 6976$ \\
\hline 4 & -4 & 2 & 79.9734 & $80 \cdot 0271$ & $76 \cdot 0547$ & $76 \cdot 3240$ & $72 \cdot 8263$ & $72 \cdot 6623$ & $65 \cdot 5644$ & 65.8734 \\
\hline 4 & -2 & 6 & 81.4756 & 81.4257 & $77 \cdot 3363$ & $77 \cdot 6072$ & $74 \cdot 7161$ & 74.5585 & 65.4907 & 65.6741 \\
\hline 2 & -2 & 10 & $84 \cdot 2207$ & 84.4012 & $80 \cdot 0429$ & $80 \cdot 3266$ & $78 \cdot 6561$ & 78.6057 & 64.9800 & $65 \cdot 3251$ \\
\hline 4 & 0 & 4 & 151.976 & $151 \cdot 592$ & $147 \cdot 519$ & $148 \cdot 044$ & $145 \cdot 131$ & 145.093 & $132 \cdot 224$ & $132 \cdot 654$ \\
\hline 0 & 0 & 12 & 153.769 & 153.674 & $148 \cdot 457$ & 148.958 & $150 \cdot 881$ & $150 \cdot 930$ & $121 \cdot 712$ & $121 \cdot 856$ \\
\hline 5 & -2 & 1 & $6 \cdot 2839$ & $6 \cdot 2724$ & $6 \cdot 2743$ & $6 \cdot 2955$ & $6 \cdot 2953$ & $6 \cdot 2996$ & 5.9092 & 5.9177 \\
\hline 4 & -3 & 7 & $14 \cdot 7651$ & $14 \cdot 7481$ & 14.6962 & 14.7439 & 14.9548 & 14.9643 & $13 \cdot 2727$ & $13 \cdot 3047$ \\
\hline 5 & -3 & 2 & 52.0971 & $52 \cdot 1265$ & 48.6049 & $48 \cdot 7626$ & $45 \cdot 4483$ & 45.4576 & $40 \cdot 3050$ & $40 \cdot 3264$ \\
\hline 3 & -1 & 10 & $45 \cdot 3467$ & $45 \cdot 7055$ & $42 \cdot 0398$ & $42 \cdot 1610$ & $39 \cdot 5644$ & $39 \cdot 6056$ & 32.4068 & 32.4676 \\
\hline 5 & -1 & 0 & $110 \cdot 637$ & $110 \cdot 846$ & $107 \cdot 523$ & $107 \cdot 772$ & $104 \cdot 350$ & $104 \cdot 610$ & $96 \cdot 1356$ & $96 \cdot 2437$ \\
\hline 5 & -2 & 4 & $114 \cdot 441$ & $114 \cdot 647$ & $111 \cdot 277$ & $111 \cdot 502$ & $108 \cdot 527$ & $108 \cdot 773$ & 98.4834 & 98.6904 \\
\hline 4 & -1 & 8 & $105 \cdot 568$ & $105 \cdot 778$ & $102 \cdot 144$ & $102 \cdot 321$ & $100 \cdot 448$ & $100 \cdot 665$ & $87 \cdot 2640$ & $87 \cdot 3380$ \\
\hline 2 & -1 & 12 & $103 \cdot 615$ & $104 \cdot 110$ & $100 \cdot 067$ & $100 \cdot 223$ & $100 \cdot 273$ & $100 \cdot 422$ & 79.6385 & $81 \cdot 1179$ \\
\hline 5 & -4 & 3 & $10 \cdot 7475$ & $10 \cdot 8279$ & $10 \cdot 8444$ & $10 \cdot 8638$ & $10 \cdot 8652$ & $10 \cdot 8947$ & $10 \cdot 0968$ & $10 \cdot 1056$ \\
\hline 5 & -1 & 3 & $10 \cdot 7475$ & $10 \cdot 8279$ & $10 \cdot 8444$ & $10 \cdot 8638$ & $10 \cdot 8652$ & $10 \cdot 8947$ & $10 \cdot 0968$ & $10 \cdot 1056$ \\
\hline 5 & -3 & 5 & $5 \cdot 1611$ & $5 \cdot 2023$ & $5 \cdot 2063$ & $5 \cdot 2131$ & $5 \cdot 2353$ & $5 \cdot 2509$ & $4 \cdot 7739$ & 4.7883 \\
\hline 4 & -2 & 9 & 0.8512 & 0.8542 & 0.8507 & $0 \cdot 8524$ & 0.8702 & 0.8717 & 0.7385 & 0.7498 \\
\hline 3 & -2 & 11 & $6 \cdot 2899$ & $6 \cdot 2288$ & $6 \cdot 1903$ & $6 \cdot 1970$ & $6 \cdot 3937$ & 6.4058 & $5 \cdot 1980$ & $5 \cdot 2903$ \\
\hline 4 & -4 & 8 & $110 \cdot 117$ & 111.064 & $108 \cdot 061$ & $108 \cdot 117$ & $107 \cdot 089$ & $107 \cdot 015$ & $90 \cdot 6055$ & 92.6618 \\
\hline 5 & -2 & 7 & $4 \cdot 3710$ & $4 \cdot 3757$ & $4 \cdot 3791$ & $4 \cdot 3789$ & 4.4067 & 4.4357 & 3.9145 & 3.9419 \\
\hline 5 & 0 & 2 & $43 \cdot 8468$ & $43 \cdot 8146$ & $41 \cdot 2971$ & $41 \cdot 3065$ & $38 \cdot 6118$ & $38 \cdot 8085$ & 33.8864 & 34.2335 \\
\hline 5 & -4 & 6 & 36.9237 & $37 \cdot 0150$ & $34 \cdot 3686$ & $34 \cdot 3925$ & 31.9058 & 32.0588 & 27.0787 & $27 \cdot 2534$ \\
\hline 5 & -1 & 6 & $36 \cdot 9237$ & $37 \cdot 0150$ & $34 \cdot 3686$ & $34 \cdot 3925$ & 31.9058 & 32.0588 & $27 \cdot 0787$ & $27 \cdot 2534$ \\
\hline 4 & -3 & 10 & $34 \cdot 0192$ & $34 \cdot 1100$ & $31 \cdot 3905$ & 31.4003 & $29 \cdot 2404$ & 29.4186 & $23 \cdot 5978$ & 23.6972 \\
\hline 1 & -1 & 14 & $34 \cdot 5234$ & $34 \cdot 5481$ & 31.7058 & 31.7523 & $30 \cdot 2643$ & $30 \cdot 4237$ & - & - \\
\hline 6 & -3 & 0 & $80 \cdot 3822$ & $80 \cdot 4326$ & 78.0268 & 78.0845 & $75 \cdot 0460$ & $75 \cdot 6357$ & $68 \cdot 3584$ & 68.6517 \\
\hline 5 & -5 & 4 & 89.4474 & 89.4923 & 86.9918 & $87 \cdot 1434$ & $84 \cdot 3891$ & $85 \cdot 0433$ & $76 \cdot 0025$ & $76 \cdot 3512$ \\
\hline 5 & -3 & 8 & 85.4306 & 85.4650 & $82 \cdot 7942$ & 82.8835 & $80 \cdot 9747$ & $81 \cdot 6455$ & - & - \\
\hline
\end{tabular}


Table 3. (continued.)

\begin{tabular}{|c|c|c|c|c|c|c|c|c|c|c|}
\hline \multirow[b]{2}{*}{$h$} & \multirow[b]{2}{*}{$k$} & \multirow[b]{2}{*}{$l$} & \multicolumn{2}{|c|}{$S 1$} & \multicolumn{2}{|c|}{$S 2$} & \multicolumn{2}{|c|}{$S 3$} & \multicolumn{2}{|c|}{$S 4$} \\
\hline & & & $F_{\mathrm{o}}$ & $F_{\mathrm{c}}$ & $F_{\mathrm{o}}$ & $F_{\mathrm{c}}$ & $F_{\mathrm{o}}$ & $F_{\mathrm{c}}$ & $F_{\mathrm{o}}$ & $F_{\mathrm{c}}$ \\
\hline 3 & -3 & 12 & $82 \cdot 0722$ & $82 \cdot 1059$ & $79 \cdot 1405$ & $79 \cdot 1891$ & $78 \cdot 7130$ & $79 \cdot 3163$ & - & - \\
\hline 3 & 0 & 12 & $82 \cdot 0722$ & $82 \cdot 1059$ & $79 \cdot 1406$ & $79 \cdot 1891$ & $78 \cdot 7130$ & $79 \cdot 3163$ & - & - \\
\hline 6 & -4 & 1 & 1.7452 & 1.7465 & $1 \cdot 7541$ & 1.7542 & 1.7423 & 1.7553 & - & - \\
\hline 6 & -3 & 3 & $12 \cdot 0192$ & $12 \cdot 0364$ & $12 \cdot 0812$ & $12 \cdot 0828$ & $12 \cdot 0207$ & $12 \cdot 1140$ & - & - \\
\hline 6 & -2 & 2 & $43 \cdot 3766$ & $43 \cdot 4030$ & $41 \cdot 2220$ & $41 \cdot 2683$ & - & - & - & - \\
\hline
\end{tabular}

Table 4. List of reliability indices (\%) after final Rietveld refinement.

\begin{tabular}{|c|c|c|c|c|}
\hline$R$-factors & $S 1$ & $S 2$ & $S 3$ & $S 4$ \\
\hline$R_{\mathrm{obs}}(\%)$ & $0 \cdot 20$ & $0 \cdot 30$ & $0 \cdot 19$ & $0 \cdot 23$ \\
\hline${ }_{\mathrm{w}} R_{\mathrm{obs}}(\%)$ & 0.32 & $0 \cdot 29$ & $0 \cdot 32$ & $0 \cdot 39$ \\
\hline$R_{\mathrm{all}}(\%)$ & $0 \cdot 20$ & $0 \cdot 30$ & $0 \cdot 19$ & $0 \cdot 23$ \\
\hline${ }_{\mathrm{w}} R_{\mathrm{all}}(\%)$ & $0 \cdot 32$ & 0.29 & $0 \cdot 32$ & $0 \cdot 39$ \\
\hline$R_{\mathrm{p}}(\%)$ & $7 \cdot 29$ & 8.49 & $4 \cdot 24$ & $4 \cdot 13$ \\
\hline${ }_{\mathrm{w}} R_{\mathrm{p}}(\%)$ & 9.83 & $11 \cdot 61$ & $5 \cdot 65$ & $6 \cdot 03$ \\
\hline
\end{tabular}

yielded low $R$-factors. This determines the accuracy of the data and their utility in calculating accurate charge density in the unit cell.

It has been proved that there is interplay between electronic and structural transition in LSMO system by Bindu et al (2008) who have investigated on the evolution of distortion in the lattice of $\mathrm{La}_{0.2} \mathrm{Sr}_{0.8} \mathrm{MnO}_{3}$ using $\mathrm{Mn} k$-edge extended X-ray absorption fine structure (EXAFS). They have found that a remarkable evolution of distortion takes place across phase transition while the system is treated between $12 \mathrm{~K}$ and $300 \mathrm{~K}$. The results show the fluctuation in Mn $3 d$ orbital occupancy during the phase transition and its implication on the electronic property of the system, the orbital and spin ordering. It is known (Bindu et al 2008) that in a system like $\mathrm{La}_{1-x} \mathrm{Sr}_{x} \mathrm{MnO}_{3}(x<0.5)$ when $\mathrm{Mn}-\mathrm{O}-$ $\mathrm{Mn}$ angle becomes close to $180^{\circ}$, the Mn- $e_{\mathrm{g}}$ orbitals become almost degenerate (Maezono et al 1998; van den Brink et al 2009). This degeneracy strongly depends on the local structure of $\mathrm{MnO}_{6}$ octahedra. Any distortion in this octahedra has an implication on the electronic properties and hence the charge and the spin ordering of the chosen material (Bindu et al 2008). When the octahedra is compressed along the apical direction, the $d$-orbital $\left(d_{x^{2}-y^{2}}\right)$ corresponding to the plane having $\mathrm{Mn}-\mathrm{O}$ bond length will be more populated compared to the perpendicular one. Also, the strong influence of disorder in $\mathrm{Mn}-\mathrm{O}$ shorter bond length that leads to hybrids in the electronic states was found to be a reason for the insulating transport in addition to the formation of zener polaron wherein a conduction electron gets trapped in between two $\mathrm{Mn}$ sites leading to a polaronic distortion. These observations indicate the relationship between the electronic properties and a change in the $\mathrm{Mn}-\mathrm{O}$ bond length that leads to a significant fluctuation in the occupancy of Mn $e_{\mathrm{g}}$-orbitals.
In the present work also, we have attempted to find a relationship between the structural distortion and the electronic properties. Beforehand, the structural investigation on the bond length in our system $\mathrm{Y}_{x} \mathrm{La}_{1-x-y} \mathrm{Sr}_{y} \mathrm{MnO}_{3}(y=0 \cdot 3)$ shows that $\mathrm{Mn}-\mathrm{O}$ bond length has become shorter as $x$ is increased from 0 to $0 \cdot 3$. An analysis on bond length shows that $\mathrm{La} / \mathrm{Sr} / \mathrm{Y}-\mathrm{O}$ bonds are of three types whereas $\mathrm{O}-\mathrm{O}$ has two bond lengths of which one is similar to La-O. In all the cases, the bond lengths have decreased as the composition $\mathrm{Y}$ in the system increases which may be attributed to the smaller size of replacement metal $\mathrm{Y}$ whose $r_{i}=1.02 \AA$ compared to $r_{i}(\mathrm{La})=1.16 \AA$ and $r_{i}(\mathrm{Sr})=1.26 \AA$. Also, the angle between $\mathrm{La}-\mathrm{O}-\mathrm{La}$ is found to be sharply decreasing from $180^{\circ}$ when $x=0$ till $x=0.3$ except for the system $x=0.2$ for which the angular distortion is more than that for the systems when $x=0 \cdot 1$ or $0 \cdot 3$. Similar type of distortion has been observed in the arrangement of $\mathrm{MnO}_{6}$ octahedra where Mn-O-Mn angle shows a decreasing behaviour starting from $x=0$ till $x=0 \cdot 3$ except for the system $x=0 \cdot 2$ (see figures 3 and 4). Thus, the distortion in $x=0.2$ is unique and therefore, it is expected that the interplay between the structural distortion at $x=0.2$ and the electronic property of this stoichiometric composition is an important one to be investigated.

\section{Charge density determination using MEM}

The structure factors extracted from the refinement were further utilized to calculate the accurate charge density in the unit cell using maximum entropy method (MEM). MEM is a very good tool for the estimation of accurate charge density and is a statistical approach proposed by Collins (1982). MEM method depends heavily on the observed information and when the information is accurate, it can be used for the reconstruction of charge density accurately and hence is known to be highly unbiased. MEM gives positive charge density everywhere and hence it gives the true charge density that can be directly analysed for any charge related properties.

In the MEM refinement, for the construction of charge density, the unit cell was divided into $54 \times 54 \times 144$ pixels and each pixel was filled with prior density equal to $F_{000} / V$. The prior density was initially used for the construction of structure factors, which would then be compared with the observed structure factors. The error in the difference in 


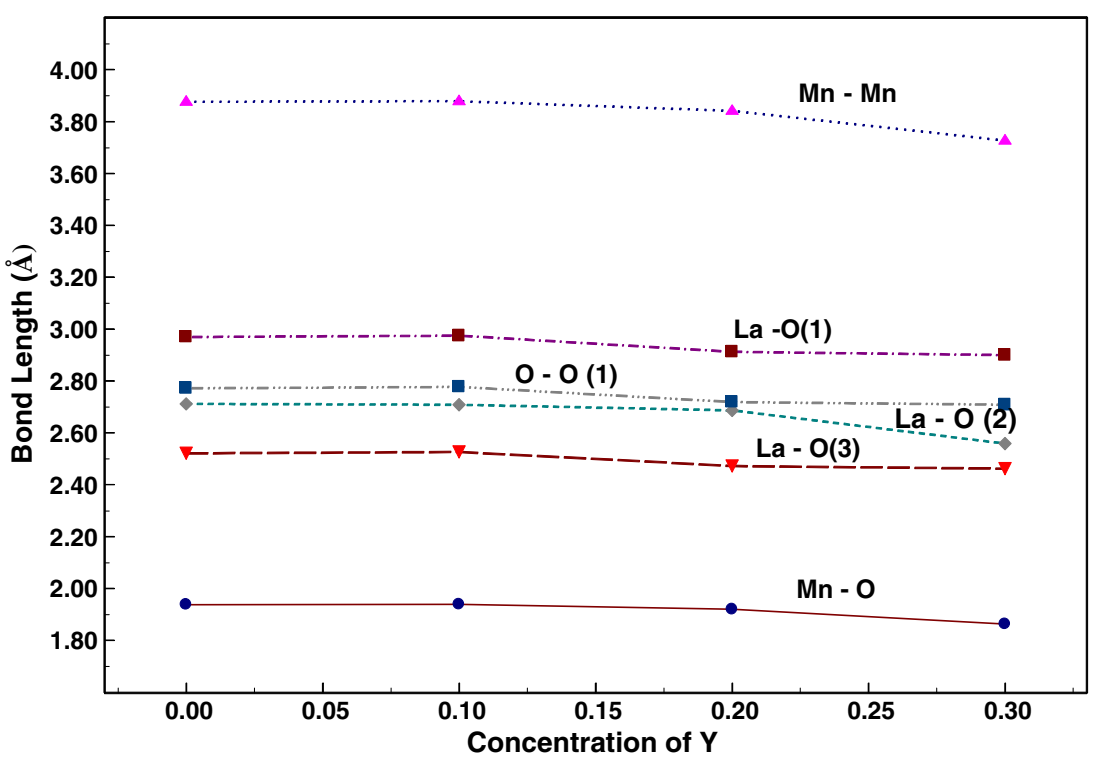

Figure 3. Graph drawn between bond length and concentration of Y.

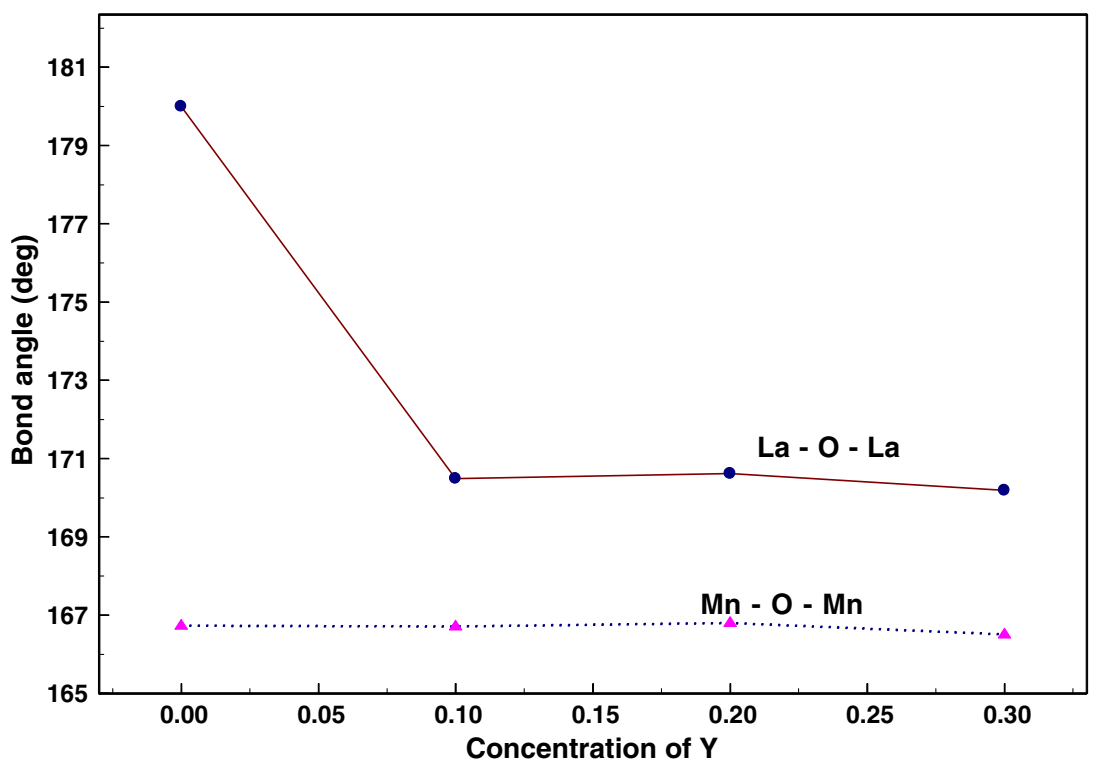

Figure 4. Graph drawn between bond angle and concentration of Y.

the structure factors was again added to the calculated ones and thus the entropy was increased. The process of increasing the entropy in the structure factors as well as in the charge density was done iteratively. The iteration would stop when the soft criterion ' $C$ ' became 1 . At this situation, the observed structure and MEM refined structure would match. The charge density constructed at this juncture using the structure factors was called the desired MEM charge density. The unique feature of this charge density is that it is real and positive. This charge density gives an accurate picture of the distribution of charges in the unit cell, which is then analysed for bonding and charge related properties of the material. The detailed methodology adopted here and the definition of the criterion used is presented in detail by Syed Ali et al (2006).

In the present work, MEM refined structure factors were elucidated using the software called PRIMA (Izumi and Dilanian 2002; Ruben and Fujio 2004) (A FORTRAN program to determine electron density by MEM from X-ray data). The parameters used in this refinement and the reliability indices were tabulated in table 5 . The phase factors evaluated by MEM and listed in table 6 were then used in the construction of the charge density in the unit cell and then visualized with the help of the visualization software called VESTA (Momma and Izumi 2008). 
Table 5. MEM refinement parameters.

\begin{tabular}{lcccc}
\hline Parameters & $S 1$ & $S 2$ & $S 3$ & $S 4$ \\
\hline Number of pixels in the unit cell & 419904 & 419904 & 419904 & 419904 \\
Number of electrons in the unit cell & 602 & 591 & 580 & 569 \\
$\lambda$ & 0.00760 & 0.00633 & 0.00845 & 0.00816 \\
Number of refinement cycles & 1776 & 2128 & 1445 & 1325 \\
$C$ & 0.99905 & 0.99977 & 0.99899 & 0.99946 \\
$R_{\mathrm{F}}$ & $0 \cdot 01153$ & 0.01140 & 0.01179 & 0.01264 \\
$w R_{\mathrm{F}}$ & $0 \cdot 01073$ & 0.01006 & 0.01120 & 0.01162 \\
\hline
\end{tabular}

Table 6. MEM refined structure factors.

\begin{tabular}{|c|c|c|c|c|c|c|c|c|c|c|}
\hline \multirow[b]{2}{*}{$h$} & \multirow[b]{2}{*}{$k$} & \multirow[b]{2}{*}{$l$} & \multicolumn{2}{|c|}{$S 1$} & \multicolumn{2}{|c|}{$S 2$} & \multicolumn{2}{|c|}{$S 3$} & \multicolumn{2}{|c|}{$S 4$} \\
\hline & & & $F_{\mathrm{obs}}(R)$ & $F_{\mathrm{MEM}}(R)$ & $F_{\mathrm{obs}}(R)$ & $F_{\operatorname{MEM}}(R)$ & $F_{\text {obs }}(R)$ & $F_{\mathrm{MEM}}(R)$ & $F_{\mathrm{obs}}(R)$ & $F_{\operatorname{MEM}}(R)$ \\
\hline 1 & -1 & 2 & $-96 \cdot 86400$ & -97.42980 & $-87 \cdot 71910$ & $-88 \cdot 17093$ & $-78 \cdot 64830$ & -79.00253 & $-96 \cdot 8640$ & -97.4298 \\
\hline 2 & -1 & 0 & $298 \cdot 88501$ & $289 \cdot 23495$ & 291.00800 & $281 \cdot 60672$ & $282 \cdot 88501$ & 274.01306 & $298 \cdot 8850$ & $289 \cdot 2349$ \\
\hline 1 & 0 & 4 & $300 \cdot 84201$ & $290 \cdot 67667$ & $292 \cdot 56500$ & 282.78946 & $286 \cdot 14499$ & $276 \cdot 39368$ & $300 \cdot 8420$ & $290 \cdot 6766$ \\
\hline 2 & -1 & 3 & -27.99340 & $-27 \cdot 95404$ & -28.00730 & $-27 \cdot 96641$ & $-28 \cdot 14740$ & $-28 \cdot 10325$ & -27.9934 & -27.9540 \\
\hline 2 & 0 & 2 & $-182 \cdot 86099$ & $-178 \cdot 76613$ & -175.75999 & $-171 \cdot 98723$ & $-168 \cdot 75700$ & $-165 \cdot 15172$ & -182.8609 & -178.7661 \\
\hline 0 & 0 & 6 & $-186 \cdot 82401$ & $-186 \cdot 59293$ & $-179 \cdot 20000$ & $-179 \cdot 02831$ & $-174 \cdot 52000$ & $-174 \cdot 27673$ & $-186 \cdot 8240$ & $-186 \cdot 5929$ \\
\hline 2 & -2 & 4 & $329 \cdot 13699$ & $315 \cdot 14847$ & $322 \cdot 62900$ & $309 \cdot 11227$ & 317.89999 & $304 \cdot 28735$ & $297 \cdot 38000$ & 284.93732 \\
\hline 3 & -1 & 1 & $-19 \cdot 22180$ & $-19 \cdot 22282$ & $-19 \cdot 27180$ & $-19 \cdot 27345$ & $-19 \cdot 28460$ & $-19 \cdot 28562$ & $-18 \cdot 57040$ & $-18 \cdot 57231$ \\
\hline 3 & -2 & 2 & $-75 \cdot 58720$ & $-75 \cdot 78486$ & $-69 \cdot 63100$ & $-69 \cdot 78431$ & $-63 \cdot 64960$ & -63.77489 & $-56 \cdot 56120$ & $-56 \cdot 69661$ \\
\hline 2 & -1 & 6 & $-70 \cdot 10670$ & $-70 \cdot 25644$ & $-64 \cdot 10100$ & $-64 \cdot 21288$ & $-58 \cdot 51450$ & -58.61178 & $-50 \cdot 60690$ & $-50 \cdot 69991$ \\
\hline 3 & 0 & 0 & $214 \cdot 11600$ & $216 \cdot 75276$ & $209 \cdot 00500$ & 211.49831 & $203 \cdot 47400$ & $205 \cdot 95647$ & 192.45100 & $195 \cdot 03755$ \\
\hline 3 & -1 & 4 & $206 \cdot 41299$ & $207 \cdot 57643$ & $201 \cdot 05800$ & $202 \cdot 15709$ & 196.43900 & 197.47969 & $182 \cdot 42400$ & $183 \cdot 64667$ \\
\hline 1 & -1 & 8 & $200 \cdot 95900$ & $203 \cdot 95462$ & 194.96700 & $197 \cdot 84657$ & 192.96300 & $195 \cdot 81483$ & $170 \cdot 06100$ & 172.60799 \\
\hline 3 & -2 & 5 & -14.45690 & -14.46274 & -14.46530 & -14.47051 & $-14 \cdot 61660$ & -14.62308 & $-13 \cdot 43240$ & -13.43704 \\
\hline 4 & -2 & 0 & $216 \cdot 75200$ & $219 \cdot 73764$ & $212 \cdot 59300$ & $215 \cdot 57376$ & 207.87199 & $210 \cdot 82867$ & 195.68100 & $198 \cdot 66862$ \\
\hline 2 & 0 & 8 & $218 \cdot 16400$ & $220 \cdot 99138$ & 213.02699 & $215 \cdot 86336$ & $212 \cdot 26199$ & $215 \cdot 02055$ & $186 \cdot 00600$ & 188.45009 \\
\hline 4 & -3 & 1 & $22 \cdot 24550$ & $22 \cdot 26476$ & $22 \cdot 33100$ & $22 \cdot 34970$ & $22 \cdot 34560$ & $22 \cdot 36598$ & $21 \cdot 19090$ & $21 \cdot 21136$ \\
\hline 3 & -1 & 7 & $11 \cdot 24940$ & $11 \cdot 25021$ & $11 \cdot 23830$ & $11 \cdot 23935$ & 11.44220 & 11.44312 & $10 \cdot 14520$ & $10 \cdot 14624$ \\
\hline 4 & -1 & 2 & $-54 \cdot 95140$ & -54.98779 & $-50 \cdot 62730$ & $-50 \cdot 66242$ & $12 \cdot 16600$ & $12 \cdot 17008$ & $-40 \cdot 75810$ & $-40 \cdot 82626$ \\
\hline 2 & -1 & 9 & $11 \cdot 86290$ & 11.86549 & $11 \cdot 81390$ & $11 \cdot 81588$ & $-46 \cdot 24320$ & $-46 \cdot 28590$ & $10 \cdot 32920$ & $10 \cdot 33013$ \\
\hline 3 & 0 & 6 & $-63 \cdot 17850$ & $-63 \cdot 16367$ & & & & & $-47 \cdot 70440$ & -47.69479 \\
\hline 3 & -3 & 6 & $-63 \cdot 17850$ & $-63 \cdot 15493$ & -58.82340 & $-58 \cdot 79358$ & $-54 \cdot 84450$ & -54.82763 & $-47 \cdot 64478$ & $-47 \cdot 70440$ \\
\hline 1 & 0 & 10 & $-56 \cdot 46470$ & $-56 \cdot 44242$ & $-52 \cdot 02240$ & $-52 \cdot 00417$ & $-48 \cdot 60000$ & $-48 \cdot 59296$ & - & - \\
\hline 4 & -3 & 4 & $145 \cdot 10500$ & $147 \cdot 08804$ & $141 \cdot 29100$ & $143 \cdot 18825$ & 137.76601 & $139 \cdot 70868$ & $126 \cdot 41100$ & $128 \cdot 17938$ \\
\hline 3 & -2 & 8 & $146 \cdot 66901$ & $148 \cdot 35056$ & $142 \cdot 45000$ & $144 \cdot 07030$ & $140 \cdot 65900$ & $142 \cdot 33714$ & $123 \cdot 18600$ & $124 \cdot 33186$ \\
\hline 4 & -1 & 5 & $17 \cdot 73780$ & $17 \cdot 74450$ & $17 \cdot 77480$ & $17 \cdot 78078$ & 17.92680 & $17 \cdot 93577$ & $16 \cdot 39790$ & $16 \cdot 40396$ \\
\hline 4 & -4 & 2 & $-80 \cdot 19090$ & $-80 \cdot 31269$ & $-76 \cdot 59610$ & $-76 \cdot 71651$ & $-72 \cdot 85230$ & -72.98491 & $-65 \cdot 92040$ & -65.98716 \\
\hline 4 & -2 & 6 & $-81 \cdot 57540$ & $-81 \cdot 80088$ & $-77 \cdot 85800$ & -78.04697 & $-74 \cdot 72410$ & -74.97234 & $-65 \cdot 68830$ & $-65 \cdot 83702$ \\
\hline 2 & -2 & 10 & $-84 \cdot 51670$ & -84.60294 & $-80 \cdot 52980$ & $-80 \cdot 61889$ & $-78 \cdot 71670$ & -78.82734 & - & - \\
\hline 4 & 0 & 4 & $152 \cdot 81200$ & $154 \cdot 17598$ & $149 \cdot 65300$ & $150 \cdot 64201$ & $146 \cdot 72501$ & 148.01175 & $134 \cdot 16299$ & $135 \cdot 37238$ \\
\hline 0 & 0 & 12 & $154 \cdot 81500$ & $154 \cdot 75652$ & $150 \cdot 45599$ & $150 \cdot 33879$ & $152 \cdot 50101$ & $152 \cdot 46671$ & $123 \cdot 09400$ & $122 \cdot 89851$ \\
\hline 5 & -2 & 1 & $-6 \cdot 14820$ & $-6 \cdot 14847$ & $-6 \cdot 17680$ & $-6 \cdot 17708$ & $-6 \cdot 18080$ & $-6 \cdot 18113$ & $-5 \cdot 80280$ & $-5 \cdot 80310$ \\
\hline 4 & -3 & 7 & $-14 \cdot 45350$ & -14.45702 & -14.46300 & -14.46594 & $-14 \cdot 68110$ & -14.68541 & -13.03920 & $-13 \cdot 04132$ \\
\hline 5 & -3 & 2 & $-52 \cdot 20320$ & $-52 \cdot 20442$ & $-49 \cdot 03220$ & $-49 \cdot 03365$ & $-45 \cdot 75120$ & $-45 \cdot 74759$ & $-40 \cdot 57240$ & -40.53955 \\
\hline 3 & -1 & 10 & $-45 \cdot 71270$ & $-45 \cdot 68018$ & $-42 \cdot 39300$ & $-42 \cdot 36577$ & $-39 \cdot 90720$ & -39.87333 & -32.73680 & $-32 \cdot 70523$ \\
\hline 5 & -1 & 0 & 111.66900 & 111.57355 & 109.00600 & $108 \cdot 85495$ & $105 \cdot 92900$ & $105 \cdot 90720$ & 97.53930 & 97.49493 \\
\hline 5 & -2 & 4 & $115 \cdot 50400$ & $115 \cdot 40400$ & $112 \cdot 75800$ & $112 \cdot 59232$ & $110 \cdot 10900$ & $110 \cdot 08731$ & 99.96580 & 99.75921 \\
\hline 4 & -1 & 8 & $106 \cdot 53200$ & $106 \cdot 27540$ & $103 \cdot 48100$ & $103 \cdot 18642$ & 101.94900 & $101 \cdot 76045$ & $88 \cdot 51510$ & 87.79919 \\
\hline 2 & -1 & 12 & $104 \cdot 83400$ & 104.61339 & $101 \cdot 34000$ & 101.08974 & 101.69300 & $101 \cdot 59943$ & $82 \cdot 17420$ & $81 \cdot 36272$ \\
\hline 5 & -4 & 3 & $10 \cdot 59540$ & $10 \cdot 59474$ & $10 \cdot 64160$ & $10 \cdot 64126$ & $10 \cdot 67210$ & $10 \cdot 67095$ & $9 \cdot 89260$ & $9 \cdot 89177$ \\
\hline 5 & -1 & 3 & $10 \cdot 59540$ & $10 \cdot 59496$ & $10 \cdot 64160$ & $10 \cdot 64130$ & $10 \cdot 67210$ & $10 \cdot 67123$ & $9 \cdot 89260$ & $9 \cdot 89211$ \\
\hline 5 & -3 & 5 & $-5 \cdot 09030$ & -5.09069 & $-5 \cdot 10620$ & $-5 \cdot 10673$ & $-5 \cdot 14350$ & $-5 \cdot 14405$ & -4.68660 & -4.68711 \\
\hline 3 & -2 & 11 & 6.09290 & $6 \cdot 09283$ & $6 \cdot 06780$ & $6 \cdot 06768$ & $6 \cdot 27400$ & $6 \cdot 27383$ & $5 \cdot 17290$ & $5 \cdot 17155$ \\
\hline
\end{tabular}


Table 6. (continued.)

\begin{tabular}{|c|c|c|c|c|c|c|c|c|c|c|}
\hline \multirow[b]{2}{*}{$h$} & \multirow[b]{2}{*}{$k$} & \multirow[b]{2}{*}{$l$} & \multicolumn{2}{|c|}{$S 1$} & \multicolumn{2}{|c|}{$S 2$} & \multicolumn{2}{|c|}{$S 3$} & \multicolumn{2}{|c|}{$S 4$} \\
\hline & & & $F_{\text {obs }}(R)$ & $F_{\operatorname{MEM}}(R)$ & $F_{\text {obs }}(R)$ & $F_{\operatorname{MEM}}(R)$ & $F_{\text {obs }}(R)$ & $F_{\operatorname{MEM}}(R)$ & $F_{\text {obs }}(R)$ & $F_{\mathrm{MEM}}(R)$ \\
\hline 4 & -4 & 8 & $111 \cdot 74100$ & 111.62278 & $109 \cdot 14400$ & $108 \cdot 94328$ & $108 \cdot 11100$ & $107 \cdot 86006$ & $93 \cdot 62620$ & $93 \cdot 23278$ \\
\hline 5 & -2 & 7 & $4 \cdot 27480$ & $4 \cdot 27440$ & $4 \cdot 28260$ & $4 \cdot 28244$ & $4 \cdot 33860$ & $4 \cdot 33807$ & $3 \cdot 85180$ & 3.85135 \\
\hline 5 & 0 & 2 & $-43 \cdot 82500$ & $-43 \cdot 82561$ & $-41 \cdot 47720$ & -41.47675 & -38.99490 & -38.99964 & $-34 \cdot 37440$ & $-34 \cdot 35764$ \\
\hline 5 & -4 & 6 & $-36 \cdot 96990$ & $-36 \cdot 93555$ & $-34 \cdot 55060$ & -34.52811 & $-32 \cdot 28200$ & $-32 \cdot 24652$ & -27.46640 & $-27 \cdot 43681$ \\
\hline 5 & -1 & 6 & $-36 \cdot 96990$ & -36.99049 & $-34 \cdot 55060$ & -34.56697 & $-32 \cdot 28200$ & $-32 \cdot 29472$ & $-27 \cdot 46640$ & -27.47366 \\
\hline 4 & -3 & 10 & -34.02210 & -34.00004 & $-31 \cdot 53300$ & $-31 \cdot 51783$ & $-29 \cdot 64120$ & $-29 \cdot 61264$ & -23.91730 & $-23 \cdot 92012$ \\
\hline 1 & -1 & 14 & -34.47770 & -34.47681 & $-31 \cdot 88820$ & $-31 \cdot 88782$ & $-30 \cdot 64360$ & $-30 \cdot 63927$ & - & - \\
\hline 6 & -3 & 0 & $80 \cdot 78130$ & $80 \cdot 46512$ & $78 \cdot 81040$ & $78 \cdot 57000$ & $76 \cdot 47470$ & $75 \cdot 88114$ & $69 \cdot 50410$ & $69 \cdot 06966$ \\
\hline 5 & -5 & 4 & 89.95310 & 89.71677 & 87.95710 & 87.79597 & $85 \cdot 94180$ & $85 \cdot 50450$ & $77 \cdot 21370$ & $76 \cdot 82559$ \\
\hline 5 & -3 & 8 & $85 \cdot 88150$ & $85 \cdot 42356$ & $83 \cdot 65330$ & $83 \cdot 29661$ & $82 \cdot 52440$ & $81 \cdot 93040$ & - & - \\
\hline 3 & -3 & 12 & $82 \cdot 47800$ & $82 \cdot 39244$ & 79.90820 & $79 \cdot 86161$ & $80 \cdot 17340$ & 79.95887 & - & - \\
\hline 3 & 0 & 12 & $82 \cdot 47800$ & $82 \cdot 22469$ & $79 \cdot 90820$ & 79.73746 & $80 \cdot 17340$ & $79 \cdot 59299$ & - & - \\
\hline 6 & -3 & 3 & $-11 \cdot 74420$ & $-11 \cdot 74210$ & -11.80330 & $-11 \cdot 80133$ & $-11 \cdot 83410$ & $-11 \cdot 82994$ & - & - \\
\hline 6 & -2 & 2 & $-43 \cdot 38010$ & $-43 \cdot 32754$ & $-41 \cdot 37450$ & $-41 \cdot 33142$ & $-39 \cdot 21420$ & $-39 \cdot 12542$ & - & - \\
\hline
\end{tabular}
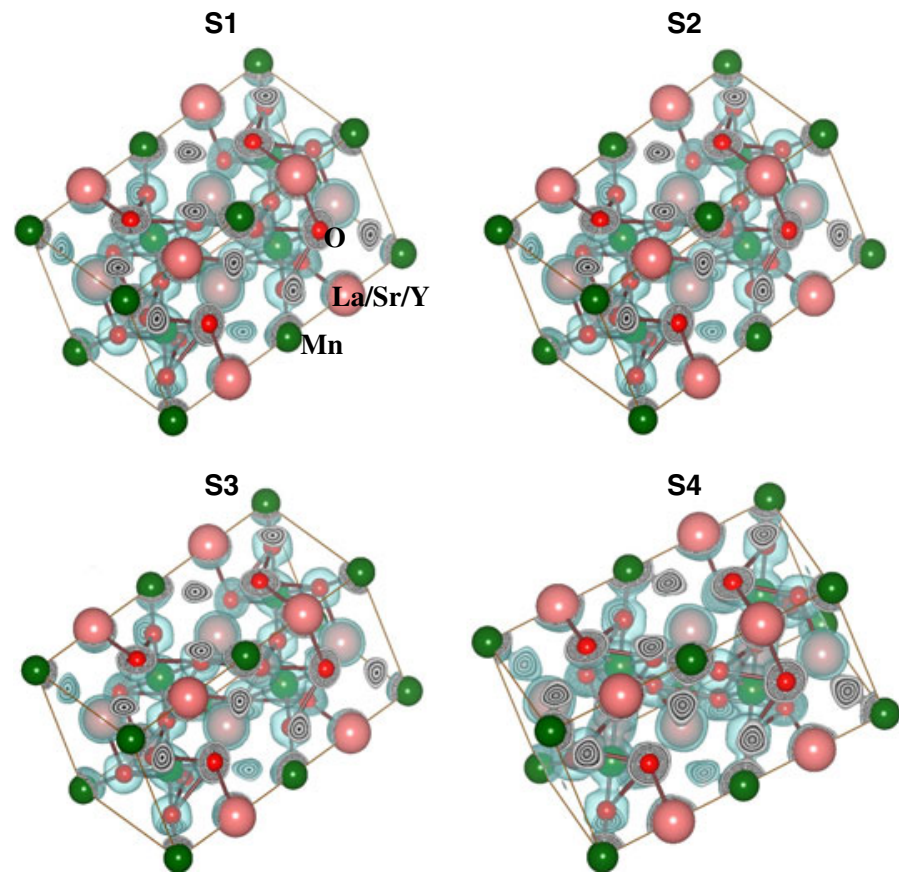

Figure 5. Three dimensional charge density in unit cell.

The charge density in the unit cell is drawn in 3-dimension for all the four samples in ball and stick model of structure and is presented in figure 5. Two dimensional miller planes are also mapped for the understanding of the bonding behaviour between $\mathrm{Mn}-\mathrm{O}, \mathrm{La}-\mathrm{O}$ and $\mathrm{O}-\mathrm{O}$ atoms and are presented in figures 6-8. One dimensional charge density profiles between the atoms are drawn to quantify the bonding character and are presented in figure 9.

The three dimensional picture of charge density with isosurface level, $0.5 \mathrm{e} / \AA^{3}$, for all the samples presented in figure 5 shows the arrangement of charges and their variations with respect to the concentration of dopant material yttrium at the lattice site of La. These pictures show that the inclusion of $\mathrm{Y}$ reduces the size of charge sphere of $\mathrm{La}$ and is primarily due to the fact that the ionic radius of $\mathrm{Y}\left(r_{i}=1.02 \AA\right)$ is smaller than that of $\mathrm{La}\left(r_{i}=1 \cdot 16 \AA\right)$. The reduction in the size of the charge sphere due to the inclusion of Y does not reflect on the global change in the lattice parameters while the angles La-O-La have been largely modified and also the $\mathrm{MnO}_{6}$ octahedra has been rearranged to include changes due to distortion. Indeed, the change in the cell dimensions can actually be attributed to the change in the electronic properties of the material particularly on a system with $x=0 \cdot 2$. While including $\mathrm{Y}$ in the lattice it has primarily rearranged 


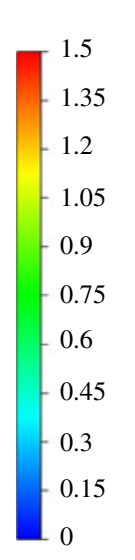

S1

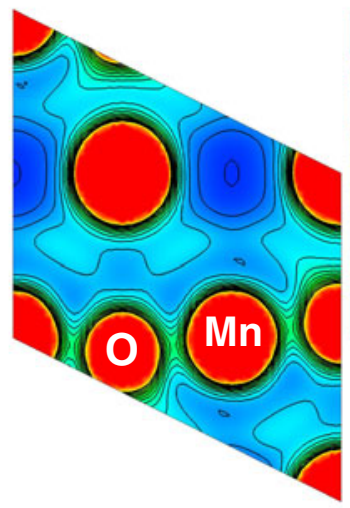

S2

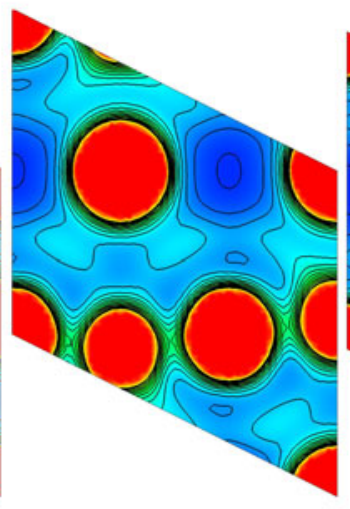

S3

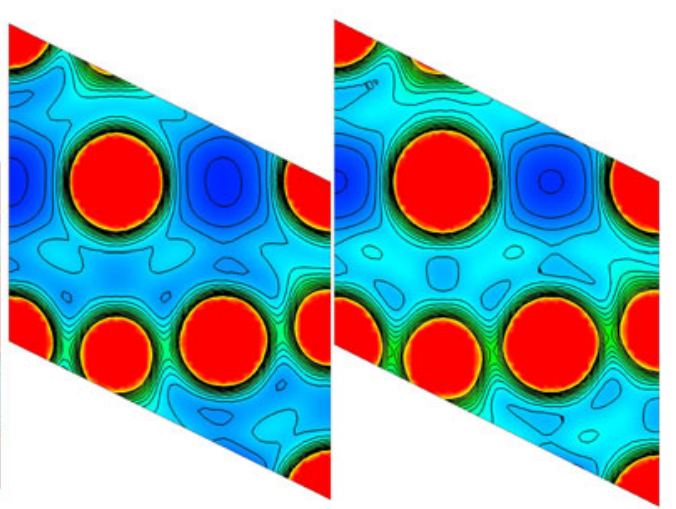

Figure 6. Two dimensional miller map showing $\mathrm{Mn}-\mathrm{O}$ bond in $\left(\begin{array}{lll}1 & 0 & 4\end{array}\right)$ plane. Contour lines are also drawn between 0 to $1.5 e / \AA^{3}$ with $0 \cdot 1 e / \AA^{3}$ interval.

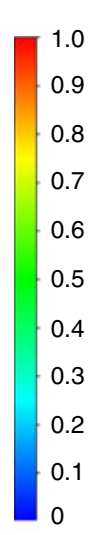

S1

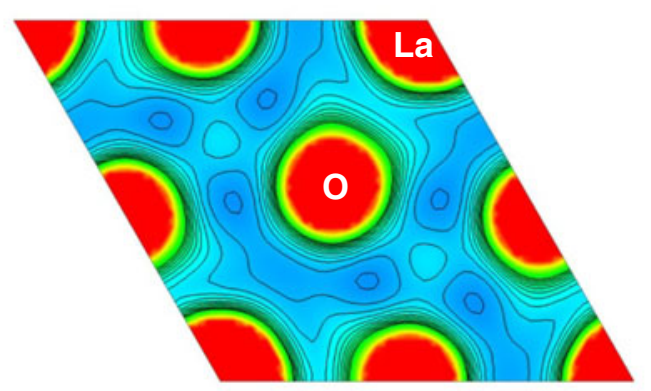

S3

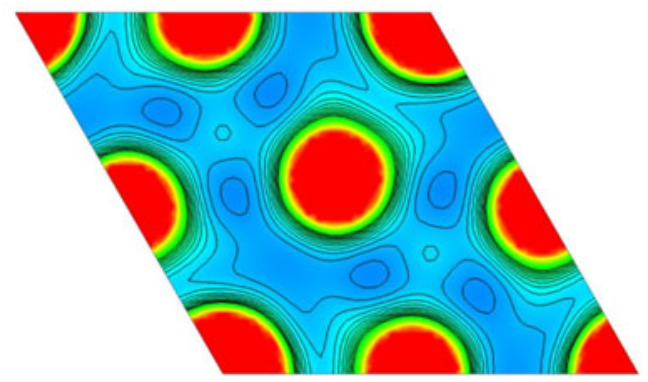

S2

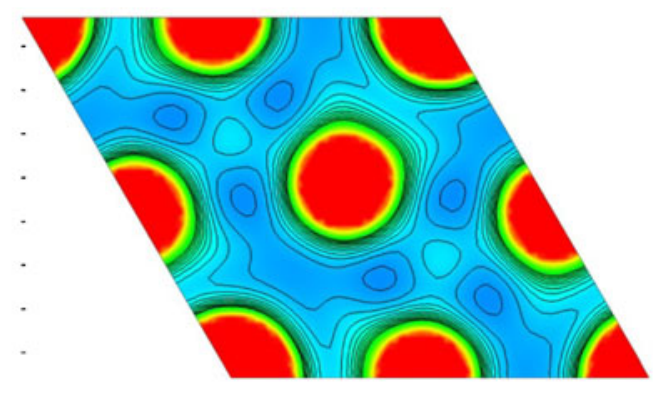

S4

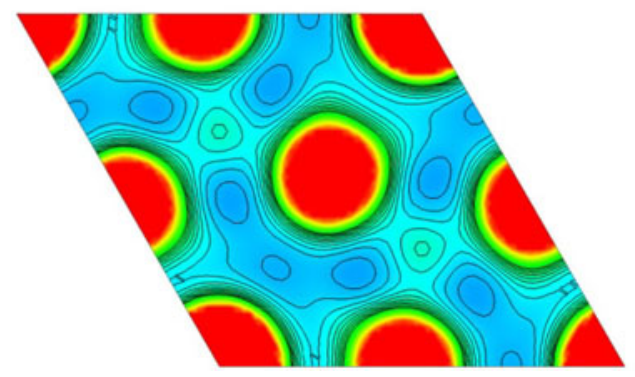

Figure 7. Two dimensional miller map showing La-O bond in $\left(\begin{array}{lll}0 & 0 & 4\end{array}\right)$ plane. Contour lines are also drawn between 0 to $1 e / \AA^{3}$ with $0.06 e / \AA^{3}$ interval.

the charge density distribution such that the changes in the cell dimensions are small. Thus figure 5 explains the change in cell dimensions as found in table 2 and also evidences the inclusion of $\mathrm{Y}$ in the samples.

\section{Insulator-metal transition}

Metal-insulator transition is a transition characterized by a sudden change in electrical transport properties (conductivity) due to a reversible change from localized to itinerant behaviour of the electrons. Doping a material can change its internal electronic structure, giving rise to or eliminating bandgaps. Materials in which a bandgap prohibits electronic conductivity are called bandgap insulators. Electron-electron interaction can also lead to the opening of an interactioninduced gap, the so-called Mott-Hubbard gap. Disorder in the material composition can lead to Anderson localization which prohibits conductivity. This is a disorder-induced metal-insulator transition even without any bandgap.

A metal-insulator transition is primarily characterized by the localization of the charge carriers, which prevent them from transporting electric current. The two basic mechanisms that cause electron localization are the correlations 


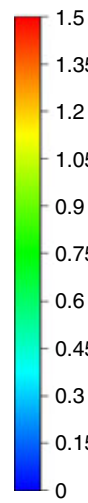

S1

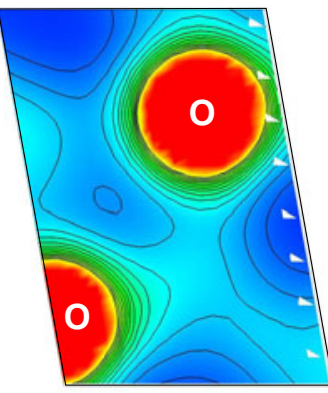

S2

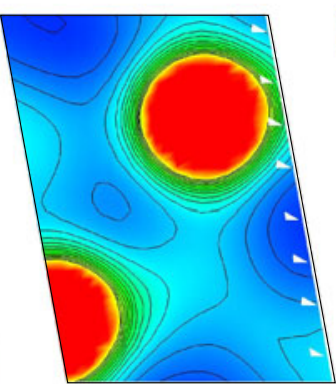

S3

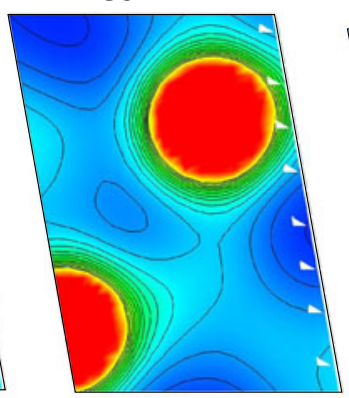

S4

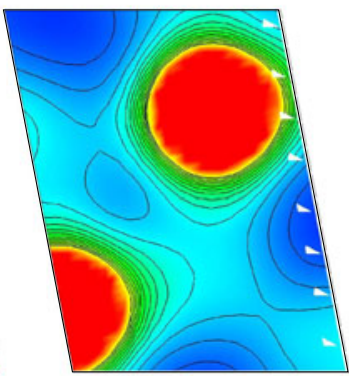

Figure 8. Two dimensional miller map showing $\mathrm{O}-\mathrm{O}$ bond in (2 2 1) plane. Contour lines are also drawn between 0 to $1.5 e / \AA^{3}$ with $0 \cdot 1 e / \AA^{3}$ interval.
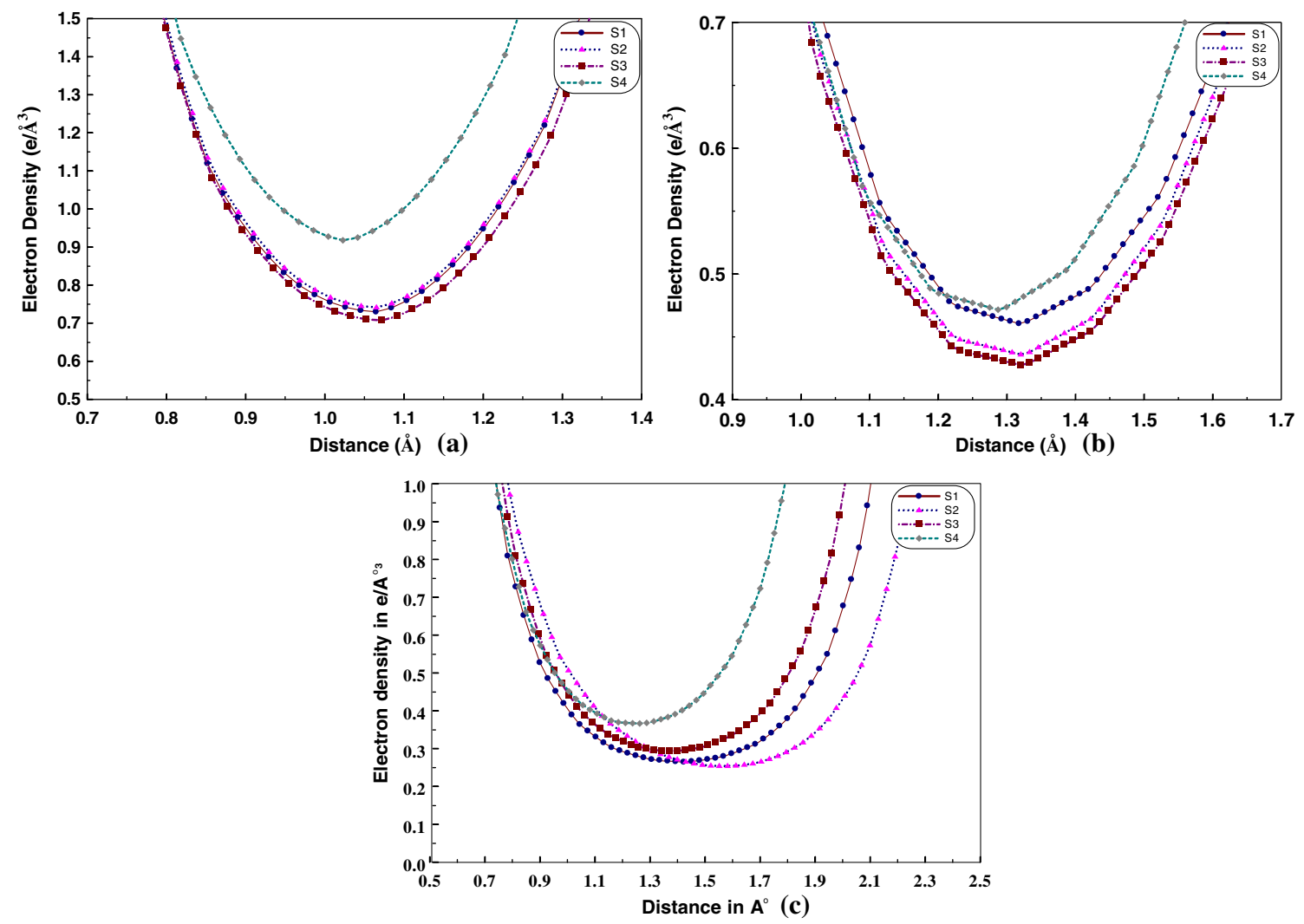

Figure 9. One dimensional electron density profile along (a) $\mathrm{Mn}-\mathrm{O}$ bond, (b) $\mathrm{La}-\mathrm{O}$ bond and (c) $\mathrm{O}-\mathrm{O}$ bond.

among the electrons and the disorder present in the sample. Mott demonstrated that electron-electron interactions can produce a metal-insulator transition even in a system without disorder (Mott 1974). Anderson discovered that a disorder, such as strong spatial fluctuations in the electrostatic potential caused by impurities, can drive a metal insulator transition in a system of non-interacting electrons (Anderson 1958). The theoretical description of the situation, when both effects are present is a central unsolved problem, especially when the electron-electron interactions are strong.
The occurrence of insulator-metal transition and then a metal-insulator transition due to the inclusion of dopant material (Y) in the stoichiometrically synthesized LSMO is a very interesting phenomenon that should be analysed with experimental tools. The electrical transport property of the material has pronounced that the insulator-metal-insulator transition happens at the composition ratio $x=0.2$ for the chosen material and this can be investigated in the charge density route. The charge density mapping is bound to give minute details about the localization and delocalization of 
the charges between the atoms when bonded. Also the effect of spatial distribution of charges from neighbouring atoms can affect the environment which leads to a change in the behaviour of localizing the charges. Thus it is expected that the presence of $\mathrm{Y}$ in some of the lattice sites of $\mathrm{La} / \mathrm{Sr}$ can induce the transition from metal/insulator to insulator/metal. The investigation of charge localization/delocalization can be done on mapping the charges in the valence region preferably in the bonding directions. It is known that the estimation of charges in the closed shell interaction (ionic) will have charges to have a perfect saddle at the mid-bond position and is low compared to the shared shell interaction (metallic/covalent) for which the mid bond will be enacted by a flattened localized charge distribution with a high charge density. This is the prime indicator that will lead to the finding of the ionic to metal transition which is otherwise called insulator-metal transition. The necessary tools for these investigations are accurate 2-D and 1-D charge density profiles.

To understand the $\mathrm{Mn}-\mathrm{O}$ bonding and the charge localization between them (lllll 04 ) plane is drawn on the unit cell with contour levels between 0 and $1.5 \mathrm{e} / \AA^{3}$ at an interval of $0.1 \mathrm{e} / \AA^{3}$ and is presented in figure 6 . Figure 6 shows bonding between $\mathrm{Mn}-\mathrm{O}$ being predominantly ionic with partial covalent character and hence a large localized charge density of about $0.8 \mathrm{e} / \AA^{3}$ is found to be present at the mid bond position. But strength of the ionicity is found to vary with respect to the charge environment at the lattice site of La. The difference in the electro negativity between $\mathrm{Mn}-\mathrm{O}$ induces ionicity in the bond with a partial covalent character and this is enhanced more due to the inclusion of $\mathrm{Y}$ in the lattice site of La. The effect of dopant material (Y) on the $\mathrm{MnO}_{6}$ polyhedra is felt in the lattice between $\mathrm{Mn}-\mathrm{O}$ and thus effectively reducing the ionicity while increasing the localized charge in the middle as the concentration of $\mathrm{Y}$ increases. Though the inclusion of $\mathrm{Y}$ in the lattice site of La does not alter the bonding nature between $\mathrm{Mn}$ and $\mathrm{O}$, it affects strength of the bond. The magnitude of the intermediate charge between Mn and $\mathrm{O}$ is found to vary alternatively for different stoichiometric compositions showing different strengths of the bond due to the doping effect (see table 7).

The effect of $\mathrm{Y}$ on the bonding between $\mathrm{La}-\mathrm{O}$ can be understood from the charge density mapping upon $\left(\begin{array}{lll}0 & 0 & 4\end{array}\right)$ plane in the unit cell. This is drawn with the contour level between 0 to $1 \mathrm{e}^{\circ} \AA^{3}$ with $0.06 \mathrm{e} / \AA^{3}$ as the interval. As the difference in electro negativity between $\mathrm{La} / \mathrm{Sr}$ and $\mathrm{O}$ is large the ionic character is well pronounced between these atoms and the maps (figure 7) also show that a perfect ionic character exists in the bonding. But this ionic character is found to increase as $x$ increases to 0.2 where the delocalization of the charges takes place. The ionic character decreases from then on as $x$ increases from 0.2 and this leads to the localization or accumulation of charges between the atoms. These behaviours are well pronounced in figure 7 . The decrease in ionic character can be attributed to the introduction of metallic character in the system and thus any decrease in the ionicity can be ascribed to the increase in the metallicity in the system. The bond critical points (BCP) and the charge density at $\mathrm{BCP}$ presented in table 7 quantify the above argument. Here, $x=0.2$ is found to be the transition point where the system makes transition from insulator to metallic.

The bonding between $\mathrm{O}-\mathrm{O}$ is observed in the plane $\left(\begin{array}{lll}2 & 2 & 1\end{array}\right)$ drawn at a distance of $1.6 \AA$ from the origin and between the contour level of 0 to $1.5 \mathrm{e} / \AA^{3}$ with $0.1 \mathrm{e} / \AA^{3}$ as interval and is presented here in figure 8 . This figure shows the covalent non-polar bonding between the oxygen atoms with the mid bond smeared owing to thermodynamic effects. The covalent charge is found to lie in a curved bond path and this introduces the so called spatial disorder, such as strong spatial fluctuations in the electrostatic potential, caused by impurities that can drive a metal/insulator to insulator/metal transition in a system of non-interacting electrons as explained by Anderson (1958). The curved bond path shown in figure 8 is the prime evidence that describes the spatial disorder in the lattice. The magnitude of the covalent charge seems to increase as $x$ increases up to 0.2 and drops when $x=0 \cdot 3$. This behaviour again evidences the fact that the spatial disorder of charges and hence the insulator - metal transition happens at $x=0 \cdot 2$.

The investigation on the bonding between $\mathrm{La} / \mathrm{Sr}$ and $\mathrm{O}$ shows that the ionicity increases from $x=0$ to 0.2 and then decreases from thereon and the same trend was again observed in the covalent non-polar bonding between $\mathrm{O}-\mathrm{O}$ as evidenced from figure 8 . The same behaviour was evidenced from the one dimensional charge density profile drawn between the atoms presented in figure 9. The quantitative evaluation of charge density at the mid bond positions between the atoms given in table 9 also evidences the trend. These pictures show that the charge ordering is taking place when yttrium is doped at the lattice site of $\mathrm{La} / \mathrm{Sr}$ at the stoichiometric composition $x=0.2$ and this result is also supported by the angular arrangement of La-O-La and $\mathrm{Mn}-\mathrm{O}-\mathrm{Mn}$ as discussed earlier. And hence it may be

Table 7. Charge density at the bond critical point.

\begin{tabular}{|c|c|c|c|c|c|c|c|c|}
\hline \multirow[b]{2}{*}{ Bond } & \multicolumn{2}{|c|}{$x=0$} & \multicolumn{2}{|c|}{$x=0 \cdot 1$} & \multicolumn{2}{|c|}{$x=0.2$} & \multicolumn{2}{|c|}{$x=0.3$} \\
\hline & $r(\AA)$ & $\rho\left(e / \AA^{3}\right)$ & $r(\AA)$ & $\rho\left(e / \AA^{3}\right)$ & $r(\AA)$ & $\rho\left(e / \AA^{3}\right)$ & $r(\AA)$ & $\rho\left(e / \AA^{3}\right)$ \\
\hline $\mathrm{La}-\mathrm{O}$ & $1 \cdot 31783$ & 0.45987 & $1 \cdot 32043$ & 0.43541 & $1 \cdot 32063$ & 0.42696 & $1 \cdot 28726$ & 0.47099 \\
\hline $\mathrm{Mn}-\mathrm{O}$ & $1 \cdot 05268$ & 0.77658 & 1.05299 & 0.78785 & 1.05939 & 0.75139 & $1 \cdot 03011$ & 0.97814 \\
\hline $\mathrm{O}-\mathrm{O}$ & 1.40394 & $0 \cdot 30773$ & $1 \cdot 38842$ & $0 \cdot 30180$ & $1 \cdot 39170$ & $0 \cdot 28849$ & $1 \cdot 31223$ & $0 \cdot 37780$ \\
\hline
\end{tabular}


assumed that material goes from insulator to metal state at $x=0 \cdot 2$. This may also be the reason for the weakening of the ferromagnetic order and increasing of the magnetic disorder owing to the presence of yttrium. Thus it is understood that the $\mathrm{Y}$ doping imposes charge delocalization and it reflects also on the weakening of the ferromagnetic order and the insulator-metal transition. Thus charge density determination can give minute details on the localization/delocalization of charges in the materials that results in the change in their physical and chemical properties.

\section{Conclusions}

Yttrium doped LSMO prepared using sol-gel technique is analysed for the effect of stoichiometric inclusion of dopant in the charge density distribution in the unit cell using Rietveld and MEM technique. The bonding between the atoms is analysed quantitatively and qualitatively. This results in insulator-metal transition at $x=0.2$ that have been studied through charge density distribution analysis for the first time. Such studies can be done to understand the charge ordering behaviour in materials that behave differently when different dopants are included in different magnetic materials.

\section{References}

Alexandrov A S and Bratkovsky A M 1999 Phys. Rev. Lett. 82141 Anderson P W 1958 Phys. Rev. 1091498

Arima T, Tokura Y and Torrance J B 1993 Phys. Rev. B48 17006

Banach G, Tyer R and Temmerman W M 2004 J. Magn. Magn. Mater 272-276 1963

Bindu R, Maiti Kalobaran, Rawat R and Khalid S 2008 Appl. Phys. Lett. 92121906

Collins D M 1982 Nature 49298

Gaur Anurag and Varma G D 2006 J. Phys. Condens. Matter 18 8837

Howard C J 1982 J. Appl. Crystallogr. 15615

Israel S, Saravanan R, Srinivasan N and Rajaram R K 2003 J. Phys. Chem. Solids 6443

Israel S, Saravanan R and Rajaram R K 2004 Physica B349 390

Izumi F and Dilanian R A 2002 Recent research developments in physics, Part II (Trivandrum: Transworld Research Network) 3 pp 699-726
Janker G H and van Santen J H 1950 Physica 16337

Krishnan K M and Ju H L 1999 Phys. Rev. B60 14793

Livesay E A et al 1999 J. Phys. Condensed Matter 11 L2711

Lyu P, Xing D Y and Dong J 1998 Phys. Rev. B58 54

Maezono R, Ishihara S and Nagaosa N 1998 Phys. Rev. B58 11583

Momma K and Izumi F 2008 J. Appl. Crystallogr. 41653

Mott N F 1974 Metal-insulator transitions (London: Taylor and Francis)

Nadgorny B et al 2001 Phys. Rev. B63 184433

Nagarajan 2008 Nature Mater. 7391

Petricek V, Dusek M and Palatinus L JANA 2000 The crystallographic computing system, Institute of Physics, Academy of Sciences of the Czech Republic, Praha

Picket W E and Singh D J 1997 J. Magn. Magn. Mater. 172237

Renuretson R 2007 Preparation and characterization of yttrium doped LSMO, M. Phil. Thesis, The American College, Madurai Kamaraj University, Madurai

Rietveld H M 1969 J. Appl. Crystallogr. 265

Ruben A D and Fujio I 2004 Super-fast program PRIMA for maximum-entropy method (Ibaraki, Japan: National Institute for Materials Science) p. 305

Saitoh T, Bocquet A E, Mizokawa T, Namatame H, Fujimori A, Abbate M, Takeda Y and Takano M 1995 Phys. Rev. B51 13942

Syed Ali K S, Saravanan R, Israel S and Rajaram R K 2006 Bull. Mater. Sci. 29107

Thompson P, Cox D E and Hastings J B 1987 J. Appl. Crystallogr. 2079

Tokura Y (ed.) 2000 Colossal magnetoresistive oxides (New York, USA: Gordon and Breach Science Publishers)

Tokura Y and Tomioka Y 1999 J. Magn. Magn. Mater. 2001

Tsai M-H, Tang Y-H, Chou H and Wu W T Private publication submitted to National Science Council of Taiwan

Urushibara A, Moritomo Y, Arima T, Asamitsu A, Kido G and Tokura Y 1995 Phys. Rev. B51 14103

Vachhani P S, Solanki P S, Markna J H, Parmar R N, Bhalodia J A and Kuberkar D G 2007 Indian J. Eng. \& Mater. Sci. 14163

van den Brink J, Khaliullin G and Khomskii D 1999 Phys. Rev. Lett. 835118

van Santen J H and Janker G H 1950 Physica 16599

Wertheim G K, Butler M A, West K W and Buchanan D N E 1974 Rev. Sci. Instrum. 451369

Xiong X, Dabrowski B, Chmaissem O, Bukowski Z, Kolesnik S, Dybzinski R, Kimball C W and Jorgensen J D 1999 Phys. Rev. B60 10186

Yakel H L 1955 Acta Crystallogr. 8394

Zheng R K, Wang Y, Chan H L W, Choy C L and Luo H S 2007 Appl. Phys. 90152904 